Supporting Information

for

\title{
Mesoporous Platinum Nanotherapeutics for Combined Chemo-Photothermal Cancer Treatment
}

\author{
Wencong Zhao, ${ }^{1}$ Zhenhua Li, ${ }^{2,3, *}$ Hua Yang, ${ }^{4}$ Cui Ren, ${ }^{1}$ Fangfang Lv, ${ }^{1}$ Shutao \\ Gao, 2,3,5 Huanyun Ma, ${ }^{6}$ Yi Jin, ${ }^{6}$ Kun Ge, ${ }^{2,3}$ Dandan Liu, ${ }^{2,3}$ Jinchao \\ Zhang ${ }^{2,3, *}$ and Huifang Liu ${ }^{1,3, *}$
}

1 College of Pharmaceutical Science, Key Laboratory of Pharmaceutical Quality Control of Hebei Province, Hebei University, Baoding 071002, China.

${ }^{2}$ College of Chemistry \& Environmental Science, Hebei University, Baoding, 071002, China.

${ }^{3}$ Key Laboratory of Medicinal Chemistry and Molecular Diagnosis of Ministry of Education, Chemical Biology Key Laboratory of Hebei Province, Hebei University, Baoding, 071002, China.

${ }^{4}$ Affiliated Hospital of Hebei University, Baoding 071000, China.

${ }^{5}$ College of Science, Hebei Agricultural University, Baoding, 071002, China.

${ }^{6}$ College of Basic Medical Science, Hebei University, Baoding 071000, China

E-mail: liu-huifang@163.com (H. Liu); jczhang6970@163.com (J. Zhang); zhenhuali@hbu.edu.cn (Z. Li). 
a

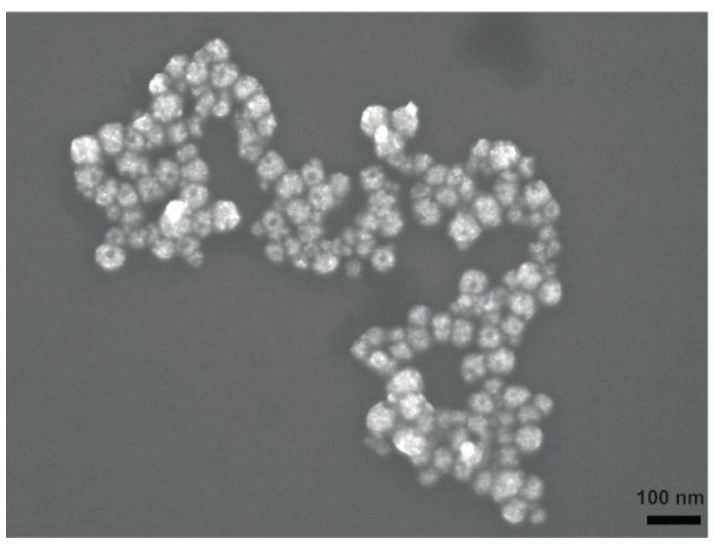

b

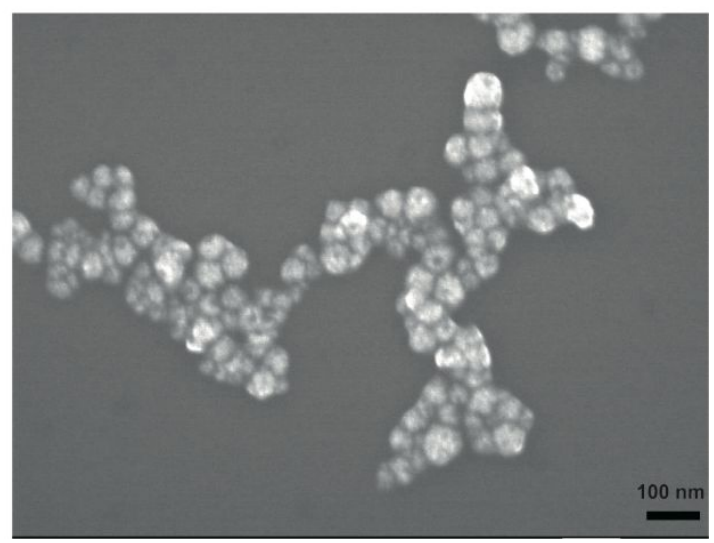

Figure S1. SEM image of (a)MPNPs and (b)MPNPs-AD-CD

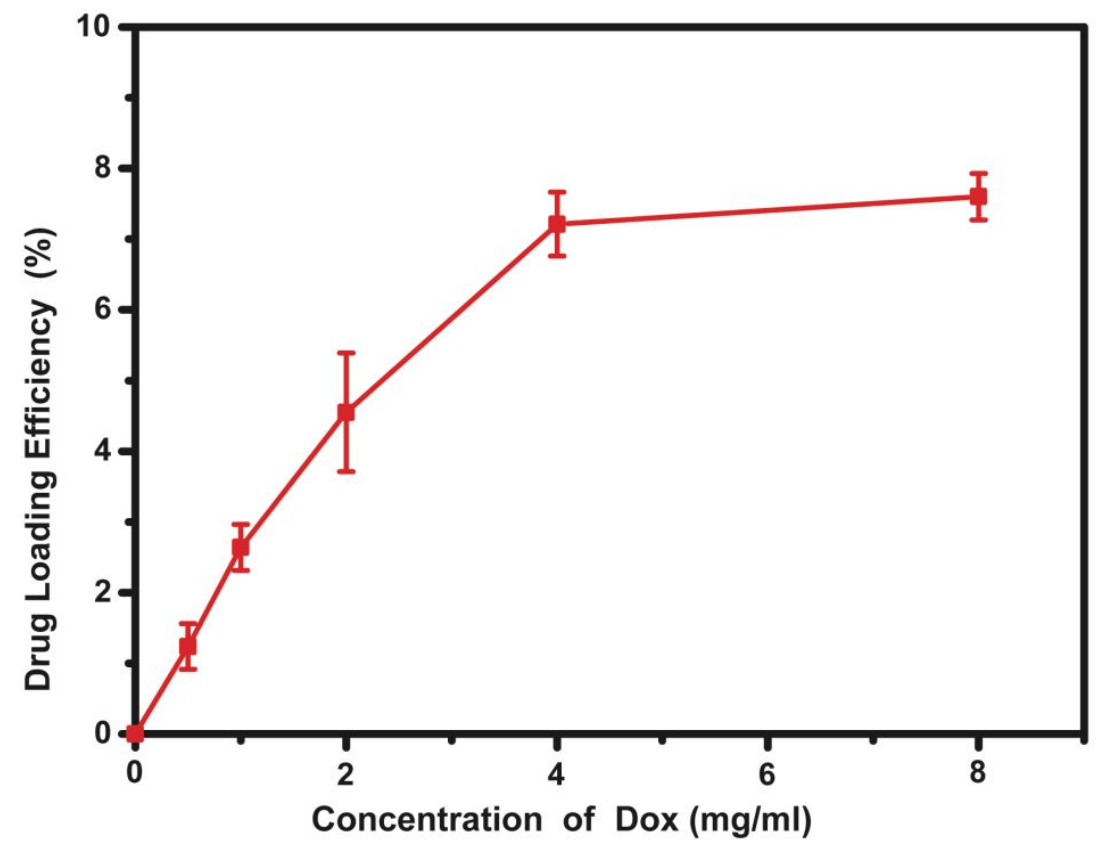

Figure S2. Loading efficiency of DOX/MPNPs-AD-CD 


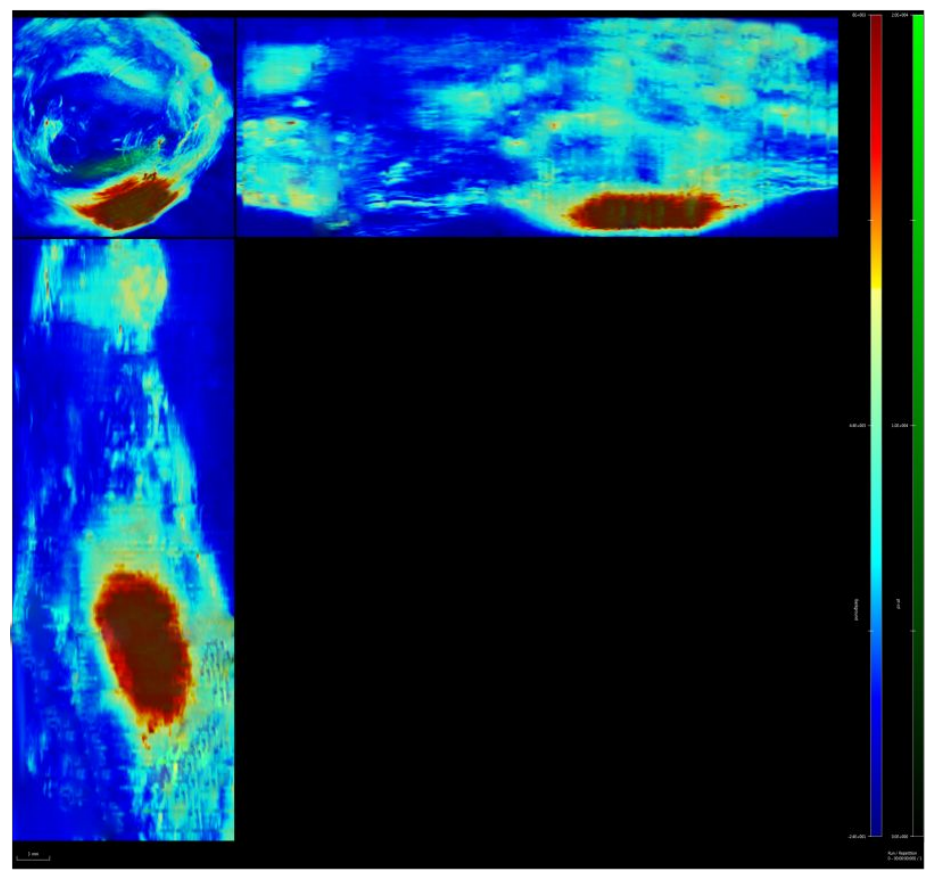

Figure S3. In vivo photoacoustic images at $24 \mathrm{~h}$ after intravenous injection of DOX/MPNPs-AD-CD.



Figure S4. Relative hemolysis after incubation of $\mathrm{H}_{2} \mathrm{O}$ (positive), $\mathrm{PBS}$ (negative) and DOX/MPNPs-AD-CD nanoparticles. ${ }^{* * *} \mathrm{p}<0.001$ analyzed by student's t-test. 


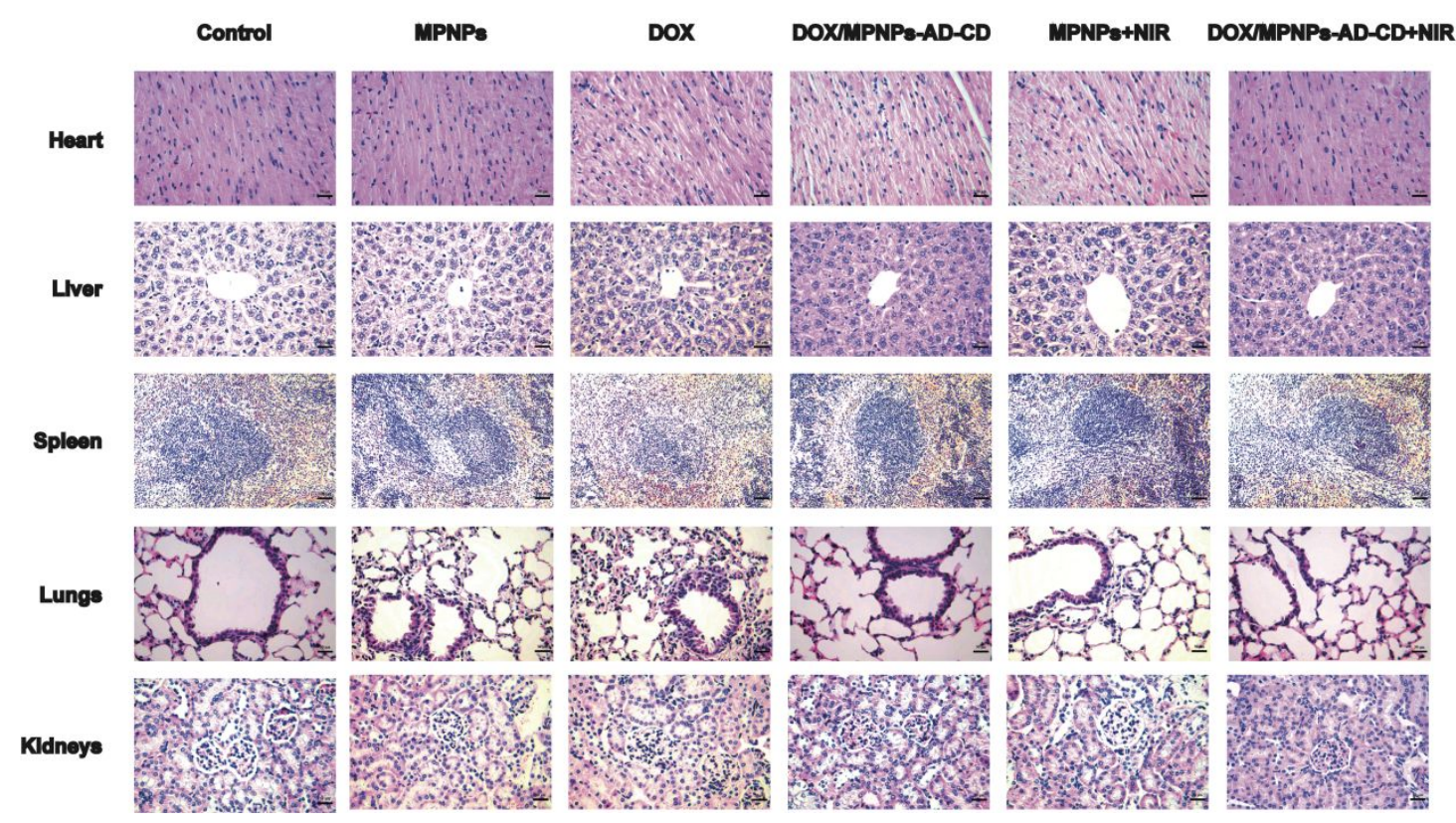

Figure S5. Histological analysis (H\&E staining images) for different organs of mice after intravenous injection (iv). 
Table S1. Blood biochemistry data of mice injected with different sample ( $\mathrm{n}=3$, mean \pm SD)

\begin{tabular}{|c|c|c|c|c|c|c|c|c|c|}
\hline Groups & $\begin{array}{c}\text { Urea } \\
(\mathrm{mmol} / \mathrm{L})\end{array}$ & $\begin{array}{c}\mathrm{Cr} \\
(\mathrm{umol} / \mathrm{L})\end{array}$ & $\begin{array}{c}\text { UA } \\
\text { (umol/L) }\end{array}$ & $\begin{array}{c}\text { CK } \\
(\mathrm{U} / \mathrm{L})\end{array}$ & $\begin{array}{l}\mathrm{HBDH} \\
(\mathrm{U} / \mathrm{L})\end{array}$ & $\begin{array}{l}\text { LDH } \\
(\mathrm{U} / \mathrm{L})\end{array}$ & $\begin{array}{l}\text { ALP } \\
(\mathrm{U} / \mathrm{L})\end{array}$ & $\begin{array}{l}\mathrm{AST} \\
(\mathrm{U} / \mathrm{L})\end{array}$ & $\begin{array}{l}\text { ALT } \\
(\mathrm{U} / \mathrm{L})\end{array}$ \\
\hline PBS & $9.0 \pm 0.6$ & $18.0 \pm 1.0$ & $205.0 \pm 40.0$ & $919.0 \pm 52.1$ & $342.7 \pm 58.6$ & $1488.7 \pm 107.0$ & $63.0 \pm 29.5$ & $184.7 \pm 10.2$ & $34.3 \pm 2.1$ \\
\hline MPNPs & $8.4 \pm 1.3$ & $16.7 \pm 0.6$ & $197.3 \pm 32.6$ & $1205.0 \pm 133.6$ & $328.3 \pm 23.7$ & $1262.0 \pm 96.4$ & $48.0 \pm 2.6$ & $190.0 \pm 12.8$ & $33.2 \pm 2.3$ \\
\hline DOX & $7.5 \pm 1.9$ & $13.0 \pm 1.8$ & $189.3 \pm 24.6$ & $1003.8 \pm 142.3$ & $366.3 \pm 94.8$ & $1423.0 \pm 115.9$ & $62.8 \pm 5.3$ & $214.5 \pm 21.5$ & $34.3 \pm 1.7$ \\
\hline MPNPs+NIR & $8.5 \pm 1.4$ & $16.5 \pm 1.3$ & $208.3 \pm 41.1$ & $1003.5 \pm 171.1$ & $351.5 \pm 52.0$ & $1282.3 \pm 277.1$ & $77.8 \pm 13.3$ & $188.0 \pm 10.1$ & $33.8 \pm 1.9$ \\
\hline DOX/MPNPs-AD-CD+NIR & $8.5 \pm 1.5$ & $16.8 \pm 2.4$ & $187.5 \pm 32.0$ & $952.0 \pm 92.7$ & $334.0 \pm 29.3$ & $1511.8 \pm 282.4$ & $60.8 \pm 5.7$ & $191.8 \pm 17.6$ & $35.5 \pm 2.6$ \\
\hline
\end{tabular}

